\title{
Feasibility of measuring sedentary time with thigh worn accelerometry, and sociodemographic correlates: the 1970 British Cohort Study
}

Mark Hamer, Emmanuel Stamatakis, Sebastien Chastin, Natalie Pearson, Matt Brown, Emily Gilbert, Alice Sullivan

Correspondence to: Professor Mark Hamer, PhD; Institute Sport Exercise \& Health, 170 Tottenham Court Road, University College London, London WC1E 6BT. (E-mail: m.hamer@ucl.ac.uk)

Author affiliations: Institute Sport Exercise \& Health, Division of Surgery \& Interventional Science, Faculty of Medical Sciences, University College London, London, UK (Mark Hamer); Charles Perkins Centre, School of Health Sciences, Faculty of Medicine and Health, University of Sydney, Sydney, Australia (Emmanuel Stamatakis); School of Health and Life Sciences, Glasgow Caledonian University, Glasgow, UK (Sebastien Chastin); School Sport Exercise Health Sciences, Loughborough University, UK (Natalie Pearson); Centre for Longitudinal Studies, Institute of Education, University College London, London, UK (Matt Brown, Emily Gilbert, Alice Sullivan).

This work was funded by British Heart Foundation grant SP/15/6/31397, and a joint award from Economic Social Research Council and Medical Research Council, grant RES-579-47-0001.

Conflict of interest: SC, NP, MB, EG, AS do not have any competing interests. ES and MH received an unrestricted grant from PAL Technologies, Scotland, UK.

Running head: Sedentary behaviour measurement

(C) The Author(s) 2020. Published by Oxford University Press on behalf of the Johns Hopkins Bloomberg School of Public Health. This is an Open Access article distributed under the terms of the Creative Commons Attribution License (http://creativecommons.org/licenses/by/4.0), which permits unrestricted reuse, distribution, and reproduction in any medium, provided the original work is properly cited. 


\section{Abstract}

In large scale cohort studies sedentary behaviour has been routinely measured using self-report or devices that apply count-based threshold. We employed a gold standard postural allocation technique using thigh inclination and acceleration to capture free-living sedentary behaviour . Participants ( $n=5,346$, aged $46.8 \pm 0.7 \mathrm{yrs}$ ) from the 1970 British Cohort study (U.K.) were fitted with a water-proofed thigh mounted accelerometer device (activPAL3 micro) worn continuously over 7 days, collected)2016 2018. Useable data were retrieved in $83.0 \%$ of the devices fitted, with $79.6 \%$ of the sample recording at least 6 full days of wear (at least 10 waking hours). Total daily sitting time (average $9.5 \pm 2.0 \mathrm{hr} / \mathrm{d}$ men and $9.0 \pm 2.0 \mathrm{hr} / \mathrm{d}$ women) accounted for $59.4 \%$ and $57.3 \%$ of waking hours in men and women respectively; $73.8 \%$ of the sample recorded $\geq 8 \mathrm{hr} / \mathrm{d}$ of sitting. Sitting in prolonged bouts of more than 60 continuous minutes accounted for $25.3 \%$ and $24.4 \%$ of total daily sitting in men and women respectively. In mutually adjusted models, male sex, underweight and obesity, education, poor selfrated health, TV-viewing time and a sitting occupation were associated with higher device measured sitting times. Thigh worn accelerometry was feasibly deployed and should be considered for larger scale national surveys.

Key words: Sedentary; Physical activity; Sitting; Lifestyle; Population Cohort study; Wearable device 


\section{Introduction}

Sedentary behaviour has been recognised as a risk factor for health (1-5). However, to date, the evidence generated from large scale population cohorts has relied on self-report with known biases (6).

Data, for example, from National Health and Nutrition Examination Survey suggested total self-reported hours per day of sitting time increased in adults from 5.5 to $6.4 \mathrm{hr} / \mathrm{d}$ during 2007 to 2016 (7) and showed that $25.7 \%$ of US adults reported more than 8 hours of total sitting time per day (8). Given the uncertainty regarding the validity of data on self-reported sitting time, it is difficult to estimate true population norms for sitting $(9,10)$.

Wearable devices are being increasingly used to assess free-living sedentary time $(11,12)$, although most of the existing methods have applied criteria based on lack of movement or movement below a certain count threshold (13). The count-based threshold approach that applies cut points to classify movement intensity can lead to misclassification of low-intensity non-sedentary behaviors such as standing (14-16). Thus, ideally sedentary time should be derived from a combination of both energy expenditure and postural elements (12).

In the present study we sought to use a thigh-mounted accelerometer device (activPAL3 micro; PAL Technologies Ltd., Glasgow, UK) to assess sedentary behavior (12). The device uses derived information about thigh inclination and acceleration to estimate body posture (i.e., sitting/lying and upright) and transition between these postures, stepping, and stepping speed (cadence). Importantly, this technique overcomesconcerns raised (14-16) about the face validity of wrist and hip worn monitors to accurately capture, postural sitting. ActivPAL was validated for measuring free-living sedentary behaviour against direct observation using an automated camera (17). Although the thigh-mounted accelerometer has been used in relatively small convenience samples thus far $(12,18)$, the present study is the first to use this approach in a large general population sample. Such studies are important to explore the feasibility 
of deploying a potentially more invasive device attached to the skin (compared to devices worn around the wrist or attached to waist belts) so that this methodology could be considered for larger scale national surveys in the future.

The aim of this study was to explore the feasibility of using a gold standard postural allocation technique to capture free-living sedentary behaviour in a large nationally representative cohort study of middleaged British adults. We firstly report on rates of consent, and adherence to the wear protocol. The second aim was to examine sociodemographic and lifestyle correlates of free-living sitting.

\section{Methods}

Design and participants

The 1970 British Cohort Study (BCS70) recruited participants born in a single week of 1970 from England, Scotland and Wales $(19,20)$. The cohort has been followed up with regular assessments throughout childhood and adulthood. The age 46 survey was a home visit conducted in 2016-18, and comprised of 50 minutes of interviews (both face-to-face computer-assisted-personal-interview and computer-assisted-self-completion-interview) with a further 50 minutes of biomedical assessments performed by trained nurses (19). Participants provided informed consent and the study received full ethical approval from NRES Committee South East Coast - Brighton \& Sussex (Ref 15/LO/1446).

Sedentary behaviour measurement 
The study used a thigh-mounted accelerometer device (activPAL3 micro; PAL Technologies Ltd., Glasgow, UK) as previously described (12). We utilised a wear protocol previously adopted (18); Devices were programmed to sample at the default frequency of $20 \mathrm{~Hz}$. The device was waterproofed and fitted by a trained nurse on the midline anterior aspect of the upper thigh as recommended by the manufacturer. Participants were requested to wear the device continuously for 7 days, including sleeping, bathing, swimming, and all physical activities. If the device fell off or was removed before the stated end date, participants were requested not to re-attach. Devices were returned via post. Data were processed using freely available software that has been previously validated (21). The software uses an algorithm to isolate valid waking wear data from sleep or prolonged non-wear. The algorithm rules have been summarized elsewhere (21). Briefly, sleep/non-wear bouts were identified as (1) the longest bout per $24 \mathrm{~h}$ period (from noon-to-noon each day) that lasted $\geq 2 \mathrm{~h}$, or (2) any very long bouts lasting $\geq 5 \mathrm{~h}$. This permits sleep/non-wear to occur at any time, any number of times (including never) within a $24 \mathrm{~h}$ window. Since sleep can register as multiple periods of sitting/lying interspersed with real or erroneously detected posture changes and stepping, the next step iteratively examined surrounding bouts and determined whether they were more likely additional sleep/non-wear (limited movement) or waking wear (more movement). Bouts were deemed 'surrounding' if any portion was within a 15 min window before or after a sleep/non-wear bout. All bouts in the sleep window were classed as sleep/non-wear when the window contained any of the following: a long (>2h) sitting/lying or standing bout, or moderately long ( $\geq 30 \mathrm{~min}$ ) with very few $(\leq 20)$ steps in between; a sleeping/non-wear bout; or, posture changes without intervening steps. This step was repeated until no further sleep/non-wear was found. We define 'Sleep' more broadly as the period a participant spent in bed, from 'into-bed' or 'lights out' time to finally awakening or arising from bed, including brief periods out of bed such as trips to the bathroom. Importantly, the algorithm was not designed to provide sub-classifications of the excluded data, such as sleep versus non-wear, or time asleep by biological definitions versus other time in bed. 
We used a step cadence threshold $\geq 100$ in order to derive moderate - vigorous intensity physical activity (22). The first partial day was removed and subsequent days were defined from midnight midnight. Participants were included if they recorded at least one valid day during the monitoring period, defined as at least $10 \mathrm{hrs}$ of waking wear time. Participants were also administered sleep diaries that were completed on a daily basis concurrently with wearing the device.

Participants provided self-reported data on context specific sedentary behaviours including TV viewing, internet use, video games, reading (all categorical: none, $<1 \mathrm{hr} / \mathrm{d}, 1-2 \mathrm{hr} / \mathrm{d}, 2-3 \mathrm{hr} / \mathrm{d}, 3-4 \mathrm{hr} / \mathrm{d}, 4-5 \mathrm{hr} / \mathrm{d}$, $\geq 5 \mathrm{hr} / \mathrm{d}$ ) car use. Data on occupational activity was derived from a combination questions on predominant activity at work (sitting, standing, physical work or heavy manual work) and information on social occupational group (Professional; Intermediate; Lower supervisory/technical; Semi-routine/ routine; Long term unemployed).

Lifestyle and health measures

Participants provided information on smoking habits (categorical; never; ex-smoker; current), self-rated health (categorical; excellent; very good; good; fair; poor), disability - using The European Statistics of Income and Living Condition classification - (categorical; none; some extent; severely hampered), and education (categorical; none; GCSE/A-level/diploma [high school]; university degree). Nurses measured height and weight for the calculation of body mass index $\left(\mathrm{kg} / \mathrm{m}^{2}\right)$, which was categorised as normal weight $(\geq 18.5<25)$, overweight $(\geq 25<30)$, obese $(\geq 30<35)$, morbidly obese $(\geq 35)$. Blood pressure was measured using automated Omron HEM-907 devices after 5 minutes of seated rest. Participants provided information on physician diagnosed hypertension and diabetes. Hypertension was defined by physician diagnosis and/or elevated systolic $(\geq 140 \mathrm{mmHg}$ ) and diastolic blood pressure ( $\geq 90 \mathrm{mmHg})$. 


\section{Statistical analyses}

The distribution of activPAL variables were examined for normality and potential outliers. The activity data represents mean hours per day averaged over the number of days the device was worn. Extreme waking hours wear time ( $n=13$; $>20 h r s$ per day) was checked against sleep diaries and in the case of clear discrepancies $( \pm 3$ SD) outliers were removed. Acceptability of the device (in terms of consent to participate and number of days worn) was examined in relation to sociodemographic characteristics. Total sitting time was categorised into tertiles (low: <8.4hr/day; medium: 8.4-10.1 hr/day; and high: $>10.1 \mathrm{hr} /$ day) and examined in relation to sociodemographic and lifestyle variables. We also derived data on bouts of uninterrupted sitting time lasting more than $60 \mathrm{~min}$. The sociodemographic and lifestyle variables were selected a priori based on existing literature $(23,24)$. Generalised linear models were used to examine associations between sociodemographic and lifestyle variables, and sitting time as a continuous dependent variable, making adjustment for waking hours wear time.

\section{Results}

Useable data were retrieved in $83.0 \%$ of the devices fitted (Web Figure 1). Participants declining to wear the device $(11.8 \%)$ were more likely to be male, smokers, report poorer health, and be obese (Web Table 1). Reasons for declining to wear the device mainly included 'inconvenience' and 'going on holiday' (plans to travel by plane was an exclusion criterion), while relatively few had concerns over attachment of the device to the skin (Web Figure 1).

The final analytic sample comprised 5,346 men and women, (aged $46.8 \pm 0.7 \mathrm{yrs}$ ). We observed high adherence to the wear protocol, $90.7 \%$ of the sample recorded at least 3 full days of device wear, $79.6 \%$ 
recorded 6 full days of wear, and $65.5 \%$ wore the device for the full 7 days. Compared to participants with higher wear adherence (> 3 days), those with poor adherence (up to 3 days) were more likely to be male, smokers, report poorer health, obese, and non-degree educated (Web Table 2). Interestingly, those with poor adherence were more likely to have worn devices over the summer months. Nevertheless, no differences were observed between the groups for average sitting time or activity.

Total daily sitting time was normally distributed (Web Figure 2) (average $9.5 \pm 2.0 \mathrm{hr} / \mathrm{d}$ men and $9.0 \pm 2.0$ $\mathrm{hr} / \mathrm{d}$ women) accounted for $59.4 \%$ and $57.3 \%$ of waking hours in men and women respectively (Table 1 ). Overall, $73.8 \%$ of the sample recorded $\geq 8 \mathrm{hr} / \mathrm{d}$ of sitting. Sitting in prolonged bouts of more than 60 continuous minutes accounted for $25.3 \%$ and $24.4 \%$ of total daily sitting in men and women respectively (Web Figure 3).

Participants recording higher sitting times were more likely male, smokers, degree educated, obese, reported higher prevalence of poor health and disability, hypertension and diabetes (Table 2). There was a trend for higher prevalence of all self-reported sedentary behaviours in the highest device measured sitting group (Table 2). The differences were particularly noticeable for TV viewing and sitting occupations. Correlations between various self-reported sedentary behaviours and the device measured daily sitting time were as follows; TV viewing $(r=0.15, p<0.001)$, internet $(r=0.12, p<0.001)$, reading $(r=0.06, p<0.001)$, occupational sitting $(r=0.36, p<0.001)$. In generalised linear models, mutually adjusted for all variables, sex, underweight and obesity, education, self-rated health, TV-viewing time and sitting occupation remained independently associated with device measured sitting time (Table 3). In particular, participants in sitting occupations recorded $2.0(95 \% \mathrm{Cl}, 1.80,2.27) \mathrm{hrs} / \mathrm{d}$ more sitting than heavy manual occupations; participants reporting more than $3 \mathrm{hr} / \mathrm{d}$ TV viewing recorded $0.89 \mathrm{hr} / \mathrm{d}(0.71$, 
1.07) extra sitting compared to $<1 \mathrm{hr} / \mathrm{d}$ TV; the morbidly obese recorded an extra $0.88 \mathrm{hr} / \mathrm{d}(0.59,1.18)$ sitting compared to normal weight. We repeated these analyses for sitting time recorded in bouts of 60 minutes or more (Table 4). The results remained largely unchanged, except seasonal differences emerged showing less prolonged sitting in spring $(B=-0.16:-0.26,-0.07)$ and summer $(B=-0.15:-0.25,-$ 0.05) compared to winter wear.

\section{Discussion}

Given the importance of obtaining accurate population measures of health behaviours for informing health policies, it is crucial to understand the feasibility of introducing novel wearable technology at large scale. In this study we demonstrate the feasibility of using a thigh worn accelerometer to capture free-living sedentary behaviour in a large nationally representative cohort study of middle-aged British adults. The thigh worn accelerometer has demonstrated superiority over other devices for measuring changes in daily sitting time. For example, Kozey-Keadle and colleagues (16) showed, compared with thigh worn activPAL, the sensitivities for the waist worn Actigraph 100 cut point and Actigraph 150 cut point were $80 \%(\mathrm{Cl}: 50 \%, 100 \%)$ and $70 \%$ (Cl: $43 \%, 97 \%)$, respectively. Specificity was $67 \%$ (CI: 39\%, 94\%) for both.

Despite attrition, the present birth cohort sample remains broadly representative (25), and characterises some of the features of contemporary western society including high prevalence of obesity and inactivity. The majority of cohort members (88.2\%) that were approached to wear the device agreed to participate; useable data were retrieved in $83.0 \%$ of the devices placed; $79.6 \%$ and $65.5 \%$ recorded at least 6 and 7 full days of wear, respectively. Our wear data are largely comparable 
with smaller activPAL studies (e.g. Senior Understanding Sedentary Patterns, n=773, 91\% with 7 days valid wear; Walking away from diabetes, $n=530,67 \%$ with 7 days valid wear; AusDiab $n=782$, 79\% with 7 days valid wear) $(12,18)$. Differences in wear compliance might be explained by characteristics of the samples and/or protocol. For example, although we largely replicated the Senior Understanding Sedentary Patterns study protocol (18) a key difference was a reliance on our participants to return their devices via post compared with monitors being removed by researchers in Senior Understanding Sedentary Patterns study. In addition, Senior Understanding Sedentary Patterns study consisted of older participants.

Our data are also comparable with large scale population data on wrist worn accelerometry in British adults; for example UK Biobank reported $93.3 \%$ of useable data from devices placed, and $80.6 \%$ of participants wore the device for at least 150 hours [ 6 days] out of a scheduled 168 hours (26). Season appeared to have influenced wear compliance in our study (lower in summer months) although no seasonal wear time differences were reported in UK Biobank (26). In addition, participants recorded greater prolonged bouts of sitting in the winter.

One of the most striking features of the present study was the markedly higher proportion of participants recording more than 8 hours of total sitting time per day compared to previous population estimates from self-report. For example, National Health and Nutrition Examination Survey showed that only $25.7 \%$ of US adults reported more than 8 hours of total self-reported sitting time per day (8) whilst our data suggested $73.8 \%$ of the sample reached this threshold. Interestingly, data on self-reported sedentary behaviours was far more comparable; for example $62 \%$ of adults from the National Health 
and Nutrition Examination Survey sample reported $>2 \mathrm{hrs} / \mathrm{d}$ TV viewing/video games (7) compared with $53 \%$ of the present British sample. Overall, this reflects the difficulties of recalling total daily sitting time.

Total sitting time was socially patterned, higher in degree educated participants. This finding is likely to be partly driven by occupation in that professionals/managers are most likely to be desk bound at work. In contrast, however, previous data suggest lower social status groups report greater sedentary behaviour in leisure time such as TV viewing (23). Thus social patterning of sedentary behaviour is likely to be context specific (not simply volume), although our data suggest it is largely driven by occupational sitting time. The other correlates of device measured sitting time, such as obesity and health indicators, found in this study are also consistent with other studies on self-reported TV viewing (24).

The main strengths of this study are the nationally representative sample, and high adherence to the wear protocol with little data loss. Our wear protocol minimised the problems of non-wear as participants were requested not to re-attach their device if removed prematurely as used previously (18). We employed a novel algorithm to isolate valid waking wear time from sleep/non-wear that enabled large volumes of accelerometry data to be processed more efficiently. Wearable activity monitors are generally designed to be worn for no more than one week to minimise participant burden, which may not adequately reflect habitual behaviour.

\section{Limitations}

As is the case in most population studies, respondents that did not consent to wear a device tended to be less educated and report poorer health that may have introduced bias. Participants with greater compliance to wearing the device were also generally healthier although device wear characteristics did 
not appear to influence the amount of sitting or activity recorded. Since our study was conducted on middle aged adults, before the onset of functional decline, it may not be representative of the wider population. The algorithm was not designed to distinguish physiological sleep periods, and in the absence of a true 'gold standard' we were unable to more fully explore sleep in this study. Data were cross-sectional and we cannot infer directionality of associations presented between sedentary and demographic characteristics. Our measure of sedentary behavior was an average of weekday and weekend activity and participants contributed differential wear time to this average. Nevertheless, average sitting times of participants with full 7 days wear were identical to data from the whole cohort.

In summary, thigh worn accelerometry can be feasibly deployed in large scale population cohorts.

Future studies should be mindful of potential selection biases when using wearable technology, both in terms of consent to participate and wear compliance. 


\section{Acknowledgements}

Author affiliations: Institute Sport Exercise \& Health, Division of Surgery \& Interventional Science, Faculty of Medical Sciences, University College London, London, UK (Mark Hamer); Charles Perkins Centre, School of Health Sciences, Faculty of Medicine and Health, University of Sydney, Sydney, Australia (Emmanuel Stamatakis); School of Health and Life Sciences, Glasgow Caledonian University, Glasgow, UK (Sebastien Chastin); School Sport Exercise Health Sciences, Loughborough University, UK (Natalie Pearson); Centre for Longitudinal Studies, Institute of Education, University College London, London, UK (Matt Brown, Emily Gilbert, Alice Sullivan).

Funding: This work was funded by British Heart Foundation grant $S P / 15 / 6 / 31397$, and a joint award from Economic Social Research Council and Medical Research Council, grant RES-579-47-0001.

Conflict of interest: SC, NP, MB, EG, AS do not have any competing interests. ES and $\mathrm{MH}$ received an unrestricted grant from PAL Technologies, Scotland, UK. 


\section{References}

1. Biswas A, Oh PI, Faulkner GE, et al. Sedentary time and its association with risk for disease incidence, mortality, and hospitalization in adults: a systematic review and meta-analysis. Ann Intern Med. 2015;162(2):123-132.

2. Schmid D, Leitzmann MF. Television viewing and time spent sedentary in relation to cancer risk: a meta-analysis. J Natl Cancer Inst. 2014;106(7)

3. Wilmot EG, Edwardson CL, Achana FA, et al. Sedentary time in adults and the association with diabetes, cardiovascular disease and death: systematic review and meta-analysis. Diabetologia. 2012;55(11):2895-2905.

4. Patterson R, McNamara E, Tainio M, et al. Sedentary behavjour and risk of all-cause, cardiovascular and cancer mortality, and incident type 2 diabetes: a systematic review and dose response meta-analysis. Eur J Epidemiol. 2018;33(9):811-829.

5. Ekelund U, Steene-Johannessen J, Brown WJ, et al; Lancet Physical Activity Series 2 Executive Committee; Lancet Sedentary Behaviour Working Group. Does physical activity attenuate, or even eliminate, the detrimental association of sitting time with mortality? a harmonised metaanalysis of data from more than 1 million men and women. Lancet. 2016;388(10051):13021310.

6. Chastin SFM, Dontje ML, Skelton DA, Čukić I, Shaw RJ, Gill JMR, Greig CA, Gale CR, Deary IJ, Der G, Dall PM; Seniors USP team. Systematic comparative validation of self-report measures of sedentary time against an objective measure of postural sitting (activPAL). Int J Behav Nutr Phys Act. 2018 Feb 26;15(1):21.

7. Yang L, Cao C, Kantor ED, Nguyen LH, Zheng X, Park Y, Giovannucci EL, Matthews CE, Colditz GA, Cao Y. Trends in Sedentary Behavior Among the US Population, 2001-2016. JAMA. 2019 Apr 23;321(16):1587-1597. 
8. Ussery EN, Fulton JE, Galuska DA, Katzmarzyk PT, Carlson SA. Joint prevalence of sitting time and leisure-time physical activity among US adults, 2015-2016. JAMA. 2018;320(19):2036-2038.

9. Stamatakis E, Ekelund U, Ding D, Hamer M, Bauman AE, Lee IM. Is the time right for quantitative public health guidelines on sitting? A narrative review of sedentary behaviour research paradigms and findings. Br J Sports Med. 2019 Mar;53(6):377-382.

10. Stamatakis E, Koster A, Hamer M, Rangul V, Lee IM, Bauman AE, Atkin AJ, Aadahl M, Matthews CE, Mork PJ, Askie L, Cistulli P, Granat M, Palm P, Crowley PJ, Stevens M, Gupta N, Pulakka A, Stenholm S, Arvidsson D, Mishra G, Wennberg P, Chastin S, Ekelund U, Holtermann A. Emerging collaborative research platforms for the next generation of physicalactivity, sleep and exercise medicine guidelines: the Prospective Physical Activity, Sitting, and Sleep consortium (ProPASS). Br J Sports Med. 2019 May 10. pii: bjsports-2019-100786. doi: 10.1136/bjsports-2019-100786. [Epub ahead of print]

11. Ndahimana D, Kim EK. Measurement Methods for Physical Activity and Energy Expenditure: a Review. Clin Nutr Res. 2017 Apr;6(2):68-80.

12. Edwardson CL, Winkler EAH, Bodiçoat DH, Yates T, Davies MJ, Dunstan DW, Healy GN. Considerations when using the activPAL monitor in field-based research with adult populations. J Sport Health Ści. 2017 Jun;6(2):162-178. doi: 10.1016/j.jshs.2016.02.002.

13. Ekelund U, Tarp S, Steene-Johannessen J, Hansen BH, Jefferis B, Fagerland MW, Whincup P, Diaz KM, Hooker SP, Chernofsky A, Larson MG, Spartano N, Vasan RS, Dohrn IM, Hagströmer M, Edwardson C, Yates T, Shiroma E, Anderssen SA, Lee IM. Dose-response associations between accelerometry measured physical activity and sedentary time and all cause mortality: systematic review and harmonised meta-analysis. BMJ. 2019 Aug 21;366:14570.

14. Rosenberger ME, Haskell WL, Albinali F, et al. Estimating activity and sedentary behaviour from an accelerometer on the hip or wrist. Med Sci Sports Exerc. 2013;45(5):964-975. 
15. Kozey-Keadle S, Libertine A, Lyden K, et al. Validation of wearable monitors for assessing sedentary behavior. Med Sci Sports Exerc. 2011;43(8):1561-1567.

16. Kozey-Keadle S, Libertine A, Staudenmayer J, Freedson P. The feasibility of reducing and measuring sedentary time among overweight, non-exercising office worker. J Obes, 2012;2012: 282-303.

17. Kim Y, Barry VW, Kang M. Validation of the ActiGraph GT3X and activPAL Accelerometers for the Assessment of Sedentary Behavior. Meas Phys Ed Exerc Sci, 2015;19(3): 125-137.

18. Dall PM, Skelton DA, Dontje ML, Coulter EH, Stewart S, Cox SR, Shaw RJ, Čukić I, Fitzsimons CF, Greig CA, Granat MH, Der G, Deary IJ, Chastin S. Characteristics of a protocol to collect objective physical activity/sedentary behaviour data in a large study: Seniors USP (understanding sedentary patterns). J Meas Phys Behav. 2018 Mar,1(1):26-31.

19. University of London loE, Centre for Longitudinal Studies. 1970 British Cohort Study: Forty-SixYear Follow-Up, 2016-2018. London, UK: UK Data Service; 2019. (http://doi.org/10.5255/UKDASN-8547-1) (accessed 11/1/2019).

20. Elliott J, Shepherd P. Cohort profile: 1970 British Birth Cohort (BCS70). Int J Epidemiol 2006;35(4):836-43.

21. Winkler EA, Bodicoat DH, Healy GN, Bakrania K, Yates T, Owen N, Dunstan DW, Edwardson CL. Identifying adults' valid waking wear time by automated estimation in activPAL data collected with a 24 h wear protocol. Physiol Meas. 2016 Oct;37(10):1653-1668.

22. Tudor-Locke C, Aguiar EJ, Han H, Ducharme SW, Schuna JM Jr, Barreira TV, Moore CC, Busa MA, Lim J, Sirard JR, Chipkin SR, Staudenmayer J. Walking cadence (steps/min) and intensity in 2140 year olds: CADENCE-adults. Int J Behav Nutr Phys Act. 2019 Jan 17;16(1):8.

23. Stamatakis E, Hillsdon M, Mishra G, Hamer M, Marmot M. Television viewing and other screenbased entertainment in relation to multiple socioeconomic status indicators and area 
deprivation: the Scottish Health Survey 2003. J Epidemiol Community Health. 2009 Sep;63(9):734-40.

24. Gardner B, Iliffe S, Fox KR, Jefferis BJ, Hamer M. Sociodemographic, behavioural and health factors associated with changes in older adults' TV viewing over 2 years. Int J Behav Nutr Phys Act. 2014 Aug 15;11:102.

25. Mostafa T, Wiggins D. Handling attrition and non-response in the 1970 British Cohort Study- CLS working paper 2014/2. June 2014. https://cls.ucl.ac.uk/wp-content/uploads/2017/04/CLS-WP2014-2.pdf (accessed 11/1/2019)

26. Doherty A, Jackson D, Hammerla N, Plötz T, Olivier P, Granat MH, White T, van Hees VT, Trenell MI, Owen CG, Preece SJ, Gillions R, Sheard S, Peakman T, Brage S, Wareham NJ. Large Scale Population Assessment of Physical Activity Using Wrist Worn Accelerometers: The UK Biobank Study. PLoS One. 2017 Feb 1;12(2):e0169649. 
Table 1. Summary descriptives ${ }^{\mathrm{a}}$ of activPAL data, 1970 British Cohort Study (2016 - 2018).

\begin{tabular}{|c|c|c|}
\hline Variable & $\begin{array}{l}\text { Men } \\
(n=2542)\end{array}$ & $\begin{array}{l}\text { Women } \\
(n=2804)\end{array}$ \\
\hline Total awake wear time $(\mathrm{hr} / \mathrm{d})$ & $15.9(1.3)$ & $15.7(1.3)$ \\
\hline Wear days & $6.1(1.6)$ & $6.2(1.5)$ \\
\hline Sitting time $(\mathrm{hr} / \mathrm{d})$ & $9.5(2.0)$ & $9.0(2.0)$ \\
\hline Prolonged sitting of bouts $60 \mathrm{~min}+(\mathrm{hr} / \mathrm{d})$ & $2.4(1.5)$ & $2.2(1.4)$ \\
\hline Standing time $(\mathrm{hr} / \mathrm{d})$ & $4.4(1.5)$ & $4.7(1.5)$ \\
\hline Total activity $(\mathrm{hr} / \mathrm{d})$ & $2.0(0.8)$ & $2.0(0.7)$ \\
\hline MVPA (min/d) & $50.4(24)$ & $51.6(24)$ \\
\hline
\end{tabular}


Table 2. Descriptive characteristics in relation to daily sitting time, 1970 British Cohort Study (2016 2018).

\begin{tabular}{|c|c|c|c|}
\hline Variable & $\begin{array}{l}\text { Low } \\
(<8.4 \mathrm{hr} / \mathrm{d}) \\
(\mathrm{n}=1791) \\
\%\end{array}$ & $\begin{array}{l}\text { Medium } \\
(8.4-10.1 \mathrm{hr} / \mathrm{d}) \\
(\mathrm{n}=1780) \\
\%\end{array}$ & $\begin{array}{l}\text { High } \\
(>10.1 \mathrm{hr} / \mathrm{d}) \\
(\mathrm{n}=1775) \\
\%\end{array}$ \\
\hline $\operatorname{Age}^{a}$ (yrs) & $46.8(0.7)$ & $46.8(0.7)$ & $46.8(0.7)$ \\
\hline \multicolumn{4}{|l|}{ Sex } \\
\hline Men & 40.0 & 46.6 & 56.1 \\
\hline Women & 60.0 & 53.4 & 43.9 \\
\hline \multicolumn{4}{|l|}{ Smoking } \\
\hline Never & 49.2 & 50.5 & 48.4 \\
\hline Past & 32.7 & 33.1 & 32.3 \\
\hline Current (occasional) & 5.1 & 4.8 & 4.2 \\
\hline Current (daily) & 13.0 & 11.6 & $15.1 y$ \\
\hline \multicolumn{4}{|l|}{ Education } \\
\hline None & 30.0 & 23.7 & 24.6 \\
\hline High school & 48.5 & 45.2 & 44.4 \\
\hline Degree & 21.5 & 31.1 & 31.0 \\
\hline \multicolumn{4}{|l|}{ Self-rated health } \\
\hline Excellent & 19.9 & 19.6 & 18.2 \\
\hline Very good & 37.9 & 39.5 & 34.5 \\
\hline Good & 28.3 & 27.0 & 27.4 \\
\hline Fair & 12.0 & 10.4 & 13.5 \\
\hline Poor & 1.9 & 3.5 & 6.4 \\
\hline \multicolumn{4}{|l|}{ Disability } \\
\hline None & 86.3 & 85.6 & 81.9 \\
\hline Some & 11.1 & 9.4 & 10.9 \\
\hline Severe & 2.6 & 5.0 & 7.2 \\
\hline \multicolumn{4}{|l|}{$\begin{array}{l}\text { Body mass index } \\
\text { category }\end{array}$} \\
\hline Underweight & 1.1 & 0.4 & 0.7 \\
\hline Healthy & 35.5 & 29.7 & 23.4 \\
\hline Overweight & 36.4 & 39.8 & 39.3 \\
\hline Obese & 24.5 & 27.8 & 32.2 \\
\hline Morbidly obese & 2.5 & 2.3 & 4.4 \\
\hline $\begin{array}{l}\text { Physician diagnosed } \\
\text { Diabetes }\end{array}$ & 1.8 & 1.5 & 3.8 \\
\hline $\begin{array}{l}\text { Physician diagnosed } \\
\text { Hypertension }\end{array}$ & 6.6 & 6.2 & 8.9 \\
\hline $\mathrm{MVPA}^{\mathrm{a}}(\mathrm{hr} / \mathrm{d})$ & $1.0(0.5)$ & $0.8(0.4)$ & $0.7(0.3)$ \\
\hline Device wear days $^{\mathrm{a}}$ & $6.1(1.7)$ & $6.3(1.4)$ & $6.1(1.6)$ \\
\hline \multicolumn{4}{|l|}{ TV viewing } \\
\hline$<1 \mathrm{hr} / \mathrm{d}$ & 18.6 & 16.0 & 13.0 \\
\hline$\geq 1<2 \mathrm{hr} / \mathrm{d}$ & 38.6 & 37.1 & 32.4 \\
\hline$\geq 2<3 \mathrm{hr} / \mathrm{d}$ & 27.7 & 28.5 & 29.1 \\
\hline
\end{tabular}




\begin{tabular}{|l|l|l|l|}
\hline$\geq 3 \mathrm{hr} / \mathrm{d}$ & 15.1 & 18.4 & 25.5 \\
\hline Video games & & & \\
\hline None & 73.4 & 70.7 & 61.6 \\
\hline$<1 \mathrm{hr} / \mathrm{d}$ & 16.4 & 18.1 & 22.2 \\
\hline$\geq 1 \mathrm{hr} / \mathrm{d}$ & 10.2 & 11.2 & 16.2 \\
\hline Internet & & & \\
\hline$<1 \mathrm{hr} / \mathrm{d}$ & 41.9 & 36.0 & 33.4 \\
\hline$\geq 1<2 \mathrm{hr} / \mathrm{d}$ & 38.8 & 39.2 & 40.7 \\
\hline$\geq 2<3 \mathrm{hr} / \mathrm{d}$ & 11.7 & 14.6 & 12.3 \\
\hline$\geq 3 \mathrm{hr} / \mathrm{d}$ & 7.6 & 10.2 & 13.6 \\
\hline Reading & & & \\
\hline None & 39.5 & 37.9 & 35.5 \\
\hline$<1 \mathrm{hr} / \mathrm{d}$ & 45.4 & 46.6 & 44.7 \\
\hline$\geq 1 \mathrm{hr} / \mathrm{d}$ & 15.1 & 15.5 & 19.8 \\
\hline $\begin{array}{l}\text { Car use for short } \\
\text { journeys }<5 \text { miles }\end{array}$ & 75.8 & 78.1 & 79.7 \\
\hline Occupational activity & & & \\
\hline Sitting & 26.7 & & \\
\hline Standing & 23.0 & 54.8 & 68.0 \\
\hline Physical work & 35.1 & 12.7 & 7.0 \\
\hline Heavy manual & 7.8 & 21.2 & 12.6 \\
\hline Unemployed & 7.4 & 2.7 & 2.4 \\
\hline
\end{tabular}

MVPA, Moderate vigorous physical activity

${ }^{a}$ values are expressed as mean (standard deviation) 
Table 3. Sociodemographic and lifestyle factors associated with device measured daily sitting (hr/d), 1970 British Cohort Study (2016 - 2018).

\begin{tabular}{|c|c|c|c|}
\hline Variable & $\mathrm{N}$ & $\mathrm{B}^{\mathrm{a}}$ & $\begin{array}{l}\text { 95\% Confidence } \\
\text { Interval }\end{array}$ \\
\hline \multicolumn{4}{|l|}{ Sex } \\
\hline Male & 2542 & Ref & \\
\hline Female & 2804 & -0.36 & $-0.46,-0.25$ \\
\hline \multicolumn{4}{|l|}{ Education } \\
\hline None & 1405 & Ref & \\
\hline High school & 2461 & 0.17 & $0.05,0.29$ \\
\hline Degree & 1480 & 0.55 & $0.42,0.69$ \\
\hline \multicolumn{4}{|l|}{ Smoking } \\
\hline Never & 2648 & Ref & 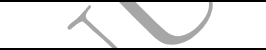 \\
\hline Ex-smoker & 1748 & 0.03 & $=0.08,0.14$ \\
\hline Current & 950 & 0.07 & $-0.08,0.24$ \\
\hline \multicolumn{4}{|l|}{ Self-rated health } \\
\hline Excellent & 1022 & Ref & 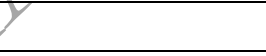 \\
\hline Very good & 1997 & 0.02 & $-0.12,0.16$ \\
\hline Good & 1478 & 0.05 & $-0.10,0.20$ \\
\hline Fair & 637 & 0.11 & $-0.08,0.31$ \\
\hline Poor & 212 & 0.96 & $0.63,1.29$ \\
\hline \multicolumn{4}{|l|}{ Disability } \\
\hline None & 4521 & Ref & \\
\hline Some extent & 561 & 0.06 & $-0.11,0.22$ \\
\hline Severely hampered & 264 & 0.76 & $0.46,1.04$ \\
\hline \multicolumn{4}{|l|}{$\begin{array}{l}\text { Body mass index } \\
\text { category }\end{array}$} \\
\hline Healthy & 1565 & Ref & \\
\hline Underweight & 109 & 0.51 & $0.16,0.87$ \\
\hline Overweight & 2032 & 0.28 & $0.16,0.40$ \\
\hline Obese & 1479 & 0.43 & $0.30,0.57$ \\
\hline Morbidly obese & 161 & 0.88 & $0.59,1.18$ \\
\hline \multicolumn{4}{|l|}{ Occupation } \\
\hline Heavy manual & 230 & Ref & \\
\hline Sitting & 2660 & 2.00 & $1.80,2.27$ \\
\hline Standing & 762 & 0.46 & $0.19,0.72$ \\
\hline Physical work & 1230 & 0.40 & $0.14,0.64$ \\
\hline Unemployed & 464 & 1.58 & $1.30,1.85$ \\
\hline \multicolumn{4}{|l|}{ TV Viewing } \\
\hline$<1 \mathrm{hr} / \mathrm{d}$ & 834 & Ref & \\
\hline$\geq 1<2 \mathrm{hr} / \mathrm{d}$ & 1890 & 0.23 & $0.08,0.38$ \\
\hline$\geq 2<3 \mathrm{hr} / \mathrm{d}$ & 1488 & 0.54 & $0.34,0.70$ \\
\hline$\geq 3 \mathrm{hr} / \mathrm{d}$ & 1134 & 0.89 & $0.71,1.07$ \\
\hline \multicolumn{4}{|l|}{ Month data collected } \\
\hline Winter & 1968 & Ref & \\
\hline
\end{tabular}




\begin{tabular}{|l|l|l|l|}
\hline Spring & 1383 & -0.09 & $-0.22,0.03$ \\
\hline Summer & 1020 & -0.12 & $-0.25,0.02$ \\
\hline Autumn & 975 & -0.06 & $-0.20,0.06$ \\
\hline
\end{tabular}

${ }^{\mathrm{a}}$ (B) Coefficients are mutually adjusted for all variables, and waking hours wear time.

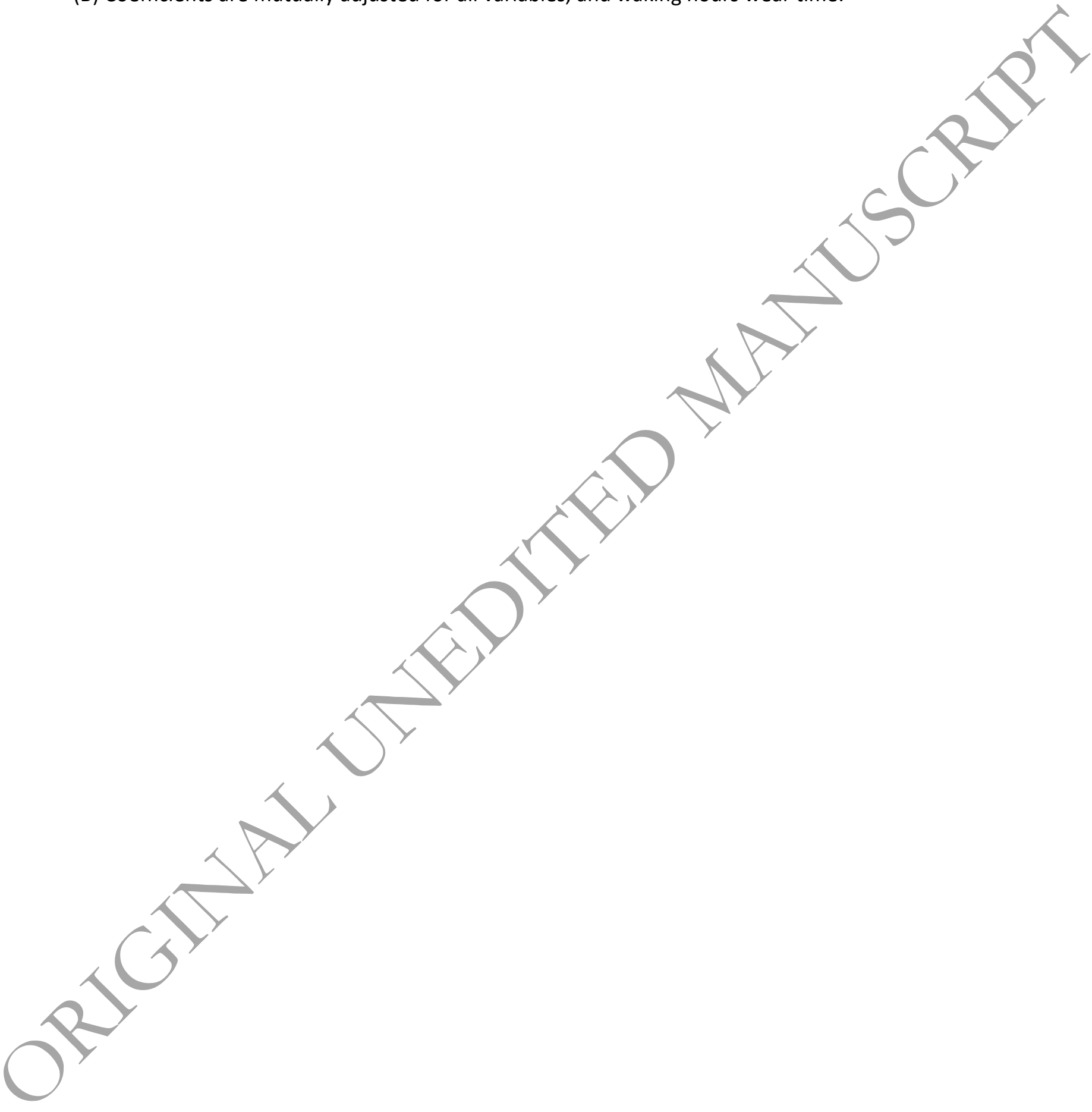


Table 4. Sociodemographic and lifestyle factors associated with device measured daily sitting in bouts of 60 minutes or more (hr/d), 1970 British Cohort Study (2016 - 2018).

\begin{tabular}{|c|c|c|c|}
\hline Variable & $\mathrm{N}$ & $\mathrm{B}^{\mathrm{a}}$ & $\begin{array}{l}\text { 95\% Confidence } \\
\text { Interval }\end{array}$ \\
\hline \multicolumn{4}{|l|}{ Sex } \\
\hline Male & 2542 & Ref & \\
\hline Female & 2804 & -0.11 & $-0.19,-0.03$ \\
\hline \multicolumn{4}{|l|}{ Education } \\
\hline None & 1405 & Ref & \\
\hline High school & 2461 & 0.04 & $-0.05,0.14$ \\
\hline Degree & 1480 & 0.19 & $0.09,0.30$ \\
\hline \multicolumn{4}{|l|}{ Smoking } \\
\hline Never & 2648 & Ref & $\mathcal{J}$ \\
\hline Ex-smoker & 1748 & -0.11 & $=0.20,-0.03$ \\
\hline Current & 950 & -0.39 & $-0.51,-0.27$ \\
\hline \multicolumn{4}{|l|}{ Self-rated health } \\
\hline Excellent & 1022 & Ref & 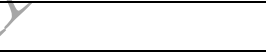 \\
\hline Very good & 1997 & 0.05 & $-0.06,0.15$ \\
\hline Good & 1478 & 0.13 & $0.01,0.24$ \\
\hline Fair & 637 & 0.18 & $0.03,0.33$ \\
\hline Poor & 212 & 0.98 & $0.72,1.23$ \\
\hline \multicolumn{4}{|l|}{ Disability } \\
\hline None & 4521 & Ref & \\
\hline Some extent & 561 & 0.06 & $-0.07,0.19$ \\
\hline Severely hampered & 264 & 0.65 & $0.44,0.87$ \\
\hline \multicolumn{4}{|l|}{$\begin{array}{l}\text { Body mass index } \\
\text { category }\end{array}$} \\
\hline Healthy & 1565 & Ref & \\
\hline Underweight & 109 & 0.57 & $0.30,0.84$ \\
\hline Overweight & 2032 & 0.15 & $0.06,0.25$ \\
\hline Obese & 1479 & 0.41 & $0.31,0.51$ \\
\hline Morbidly obese & 161 & 0.87 & $0.64,1.09$ \\
\hline \multicolumn{4}{|l|}{ Occupation } \\
\hline Heavy manual & 230 & Ref & \\
\hline Sitting & 2660 & 0.56 & $0.36,0.74$ \\
\hline Standing & 762 & 0.01 & $-0.19,0.22$ \\
\hline Physical work & 1230 & -0.02 & $-0.21,0.17$ \\
\hline Unemployed & 464 & 0.64 & $0.41,0.87$ \\
\hline \multicolumn{4}{|l|}{ TV Viewing } \\
\hline$<1 \mathrm{hr} / \mathrm{d}$ & 834 & Ref & \\
\hline$\geq 1<2 \mathrm{hr} / \mathrm{d}$ & 1890 & 0.11 & $0.002,0.23$ \\
\hline$\geq 2<3 \mathrm{hr} / \mathrm{d}$ & 1488 & 0.30 & $0.18,0.42$ \\
\hline$\geq 3 \mathrm{hr} / \mathrm{d}$ & 1134 & 0.58 & $0.44,0.71$ \\
\hline \multicolumn{4}{|l|}{ Month data collected } \\
\hline Winter & 1968 & Ref & \\
\hline
\end{tabular}




\begin{tabular}{|l|l|l|l|}
\hline Spring & 1383 & -0.16 & $-0.26,-0.07$ \\
\hline Summer & 1020 & -0.15 & $-0.25,-0.05$ \\
\hline Autumn & 975 & -0.08 & $-0.19,0.02$ \\
\hline
\end{tabular}

${ }^{\mathrm{a}}$ (B) Coefficients are mutually adjusted for all variables, and waking hours wear time.

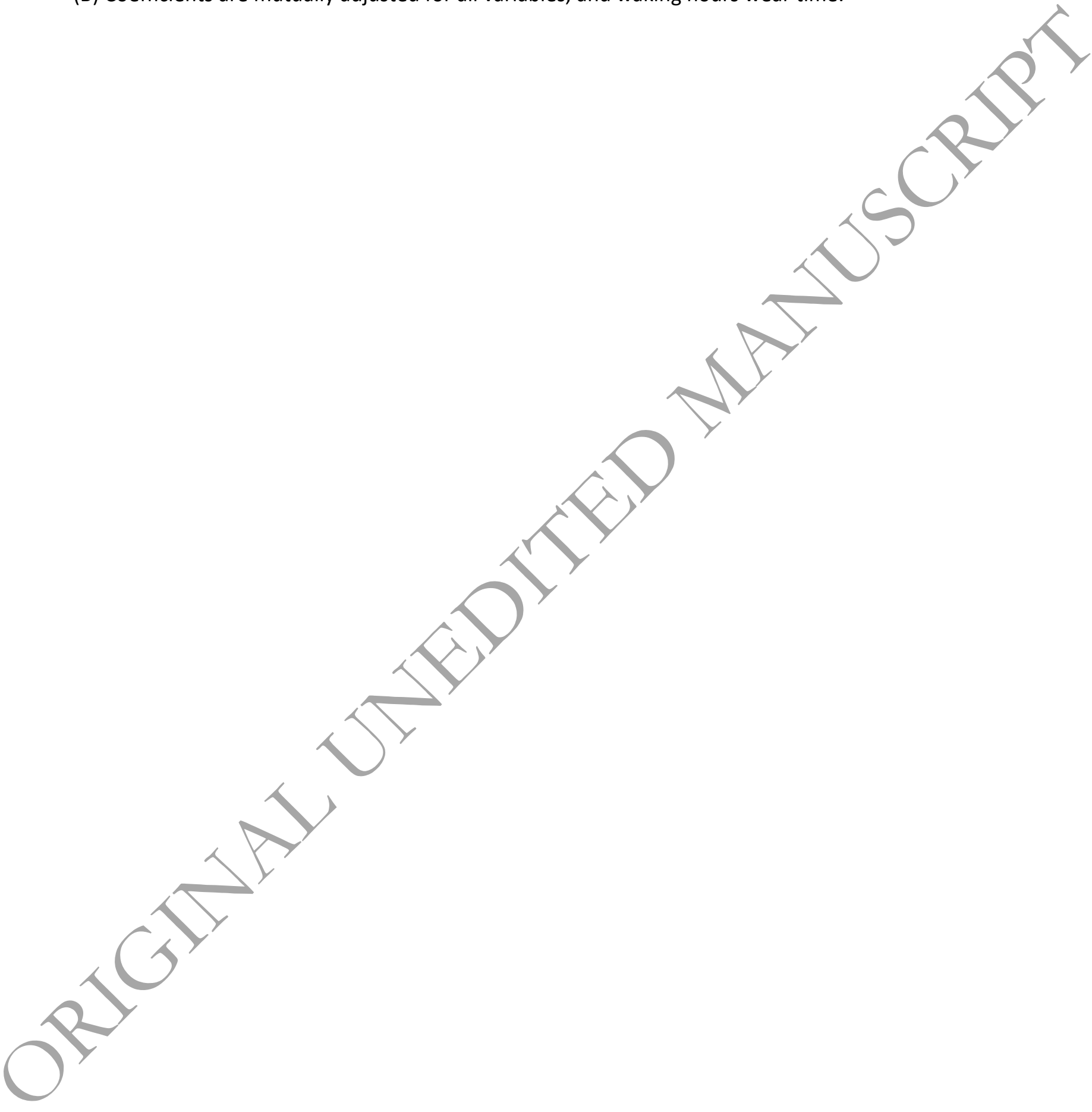

